\title{
Modelagem de Dados Radar de Penetração no Solo em Tubulações Com Fluidos
}

Gleide Nascimento Dias Alencar (UFRJ), Anna Letícia Espíndola de Oliveira (UFRJ), Marco Antônio da Silva Braga

Copyright 2018, SBGf - Sociedade Brasileira de Geofísica

Este texto foi preparado para a apresentação no VIII Simpósio Brasileiro de Geofísica, Salinópolis, 18 a 20 de setembro de 2018. Seu conteúdo foi revisado pelo Comitê Técnico do VIII SimBGf, mas não necessariamente representa a opinião da SBGf ou de seus associados. E proibida a reprodução total ou parcial deste material para propósitos comerciais sem prévia autorização da SBGf.

\section{Resumo}

Neste trabalho é demonstrada a aplicação de modelos sintéticos para tubulações de PVC, aço, concreto e cerâmica preenchidos com ar, água e gasolina. $\mathrm{O}$ conhecimento da localização das redes subterrâneas em profundidade e diâmetro se mostra importante em diferentes áreas principalmente em Engenharia Civil, para que possam ser protegidas durante a escavação e a construção. Nos modelos são simulados a aquisição e verificado a resposta do método geofísico Radar de Penetração no Solo (GPR) o qual se baseia na propagação de ondas eletromagnéticas em altas frequências. A modelagem dos dados é fundamentada nas FDTD (Diferenças Finitas no Domínio do Tempo) que se mostra uma ferramenta eficaz devido a sua precisão, flexibilidade e visualização de resultados. Foram realizadas seis simulações de aquisições de dados no modo common-offset (COS) com antenas biestáticas de $100 \mathrm{MHz}$, as propriedades das respostas eletromagnéticas das tubulações subterrâneas foram determinadas, sob condições de solo conhecidas. Os modelos foram construídos variando-se a profundidade das tubulações e com tubulações em uma mesma profundidade. Nos resultados se pode destacar a presença da água e a constituição do tubo em aço que apresentaram alta amplitude em comparação as demais tubulações e tipos de fluidos. A utilização da migração Kircchoff nas simulações posicionou os resultados hiperbólicos da difração em seu verdadeiro ponto refletores.

\section{Introdução}

A localização, dimensão, tipo de tubulação, conexões e terminações das redes de água, esgoto, gás e eletricidade, internet e etc. são importantes para elaboração de projetos a fim de evitar danos e planejar reparos. Em saneamento básico tem-se a captação de água, adução e distribuição de águas de abastecimento urbano e industrial, além dos sistemas de controle sanitário e de drenagem fluvial. Dentro da engenharia ambiental os cursos de água são destinados à preservação dos ecossistemas aquáticos, dispersão de poluentes, problemas relacionados com erosão e assoreamento, entre outros. De fato em função da necessidade essencial da água, gás, cabos de eletricidade e etc., para a infra-estrutura da população esses se distribuem de forma irregular no tempo e espaço, onde se faz o seu transporte de onde está disponível até os locais onde seu uso é necessário.
Em auxilio a essa estrutura complexa o método geofísico Ground Penetrating Radar (GPR) pode ser usado na caracterização de alvos rasos (tubulações) enterrados, sendo considerada uma técnica não destrutiva para investigar a condições dos tubos e sua localização.

\section{Método}

O método geofísico Ground Penetrating Radar (GPR) pode ser utilizado na caracterização de alvos rasos (tubulações) enterrados. Segundo Zeng and McMechan (1997), estudos anteriores mostram a viabilidade do uso do GPR associado a outros métodos para detecção e interpretação das propriedades dos objetos enterrados e, além disso, modelos sintéticos podem contribuir para o planejamento de experimentos de campo (escolha de frequências e separações de antenas ideais). O método GPR baseia-se na propagação de ondas eletromagnéticas (EMs) em altas frequências (1 $\mathrm{MHz}$ a $2500 \mathrm{MHz}$ ) (Dias, 2007). O princípio básico do funcionamento do GPR é o uso de uma antena transmissora dipolar disposta sobre a superfície o qual emite pulsos eletromagnéticos para dentro do solo e ao encontrar mudanças nas propriedades físicas (permissividade dielétrica relativa, permeabilidade magnética e condutividade elétrica) entre os materiais em subsuperficie, o sinal é refletido e registrado em tempo duplo (tempo de ida e volta) por outra antena receptora, também disposta na superfície. Para se obter os dados GPR, as antenas, transmissora e receptora, podem ser movidas ao longo de um perfil através de incrementos espaciais, resultando assim, em uma imagem baseada nas variações laterais das propriedades físicas dos materiais em subsuperficie em função do tempo de percurso da onda (Rodrigues, 2004).

A modelagem é uma representação matemática da distribuição espacial de características vinculadas a superfícies reais. Entre os tipos de modelagens numéricas pode-se ressaltar o método de Diferenças Finitas no Domínio do Tempo (FDTD - Finite Difference Time Domain). O FDTD é um dos vários métodos computacionais que visam resolver numericamente as equações diferenciais de Maxwell que descrevem a propagação, transmissão e espalhamento das ondas eletromagnéticas em um meio qualquer e que na maioria dos casos estão submetidos a condições de contorno (Wexler, 1969). O método consiste em uma técnica de aproximações sucessivas que transforma as equações diferenciais em equações discretizadas ou finitas, através do conceito da aproximação da derivada central de um ponto (Figura 1 e equação 1) acrescido do incremento temporal $\mathrm{t}$ e expandido em série de Taylor (equação 2) até atingir um erro estipulado pelo truncamento, após um dado número de interações. A função fonte utilizada para a modelagem também pode ser a derivada da função gaussiana e o tempo é descrito com intervalo de amostragem em nanosegundos. 
$\frac{\partial f(x o)}{\partial x} \approx \frac{f(x o+\Delta x)-f(x o-\Delta x)}{2 \Delta x}$

$F^{n}(i, j, k)=F(i \Delta, j \Delta, k \Delta, n \Delta t)$

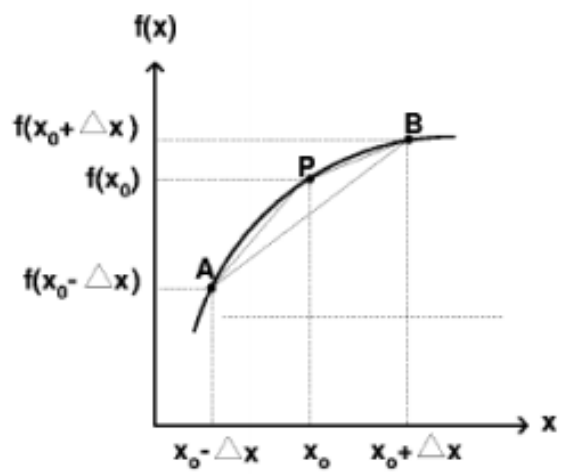

Figura 1 - Gráfica para definição genérica de derivada central de um ponto para uma função $f(x)$ em um ponto $P$ qualquer (Lima, 2006).

Um fator importante na modelagem é uso das condições de contorno absorvente. Embora, em situações reais a área de estudo possua extensão infinita no algoritmo computacional FDTD é necessário implementar limites ao domínio do cálculo, visando diminuir a memória computacional requerida. Para isso, são utilizadas condições nos limites da malha as quais simulam propagações no infinito, evitando dessa maneira reflexões espúrias das ondas que incidam nas paredes do modelo sintético (Taflove, 1980).

A migração é o processo que move as energias de reflexão das localizações aparentes para as localizações verdadeiras. Para o estudo em questão foi utilizada a migração Kirchhoff que utiliza a forma integral da equação de onda e baseia-se no princípio de Huygens, segundo o qual, o refletor sísmico (eletromagnético) é visto como se fosse composto de difrações pontuais, sendo o ápice da curva de difração a localização do verdadeiro ponto refletor. $\mathrm{O}$ propósito da migração de Kirchhoff é resumir a energia produzida por cada fonte secundária de Huygens e mapeá-la em ponto de geração. Desta forma, cada ponto na seção migrada é tratado independentemente dos outros pontos. Cada ponto na seção migrada de saída é produzido adicionando todos os valores de dados ao longo de uma difração que é centralizada nesse ponto. $O$ método de soma de difração soma as amplitudes de eventos sísmicos (eletromagnéticos) conforme registradas. No procedimento de migração de Kirchhoff, o objetivo é encontrar a solução para a equação de onda escalar para a função de onda $(x, z, t)$. Resolvendo a equação de onda, a aproximação de campo distante considerada na migração de Kirchhoff pode ser expressa como a equação abaixo:

$$
\begin{aligned}
& \mathrm{P}(\mathrm{r}, \mathrm{t})= \\
& \frac{1}{2 \pi} \int d t_{o} \int d A_{o} \frac{\cos \theta}{r}\left[\left(\frac{1}{v}\right) u^{\prime}\left(r_{o}, t_{o}\right)+\left(\frac{1}{r}\right) P\left(r_{o}, t_{o}\right)\right]
\end{aligned}
$$

Onde, $t_{0}=\mathrm{t}-(\mathrm{r} / \mathrm{v})$. A equação acima contém claramente os fatores de obliquidade $(\cos \varnothing)$ e de divergência esférica $(1 / r)$ entre seus termos. $O$ segundo termo nesta equação, $(1 / r)$ u ( $\left.r_{0}, t_{0}\right)$ é geralmente abandonado, porque é proporcional a $1 / \mathrm{r}^{2}$ (Smitha et al, 2016).

\section{Metodologia}

Foram realizadas seis simulações de aquisições de dados no modo common-offset (COS) com antenas biestáticas de frequência de $100 \mathrm{MHz}$ com janela de tempo duplo em 512 ns. Para a simulação do método GPR com as tubulações foi utilizado o software REFLEXW. O modelo sintético utilizado que representa o meio geológico possui $25 \mathrm{~m}$ de extensão e $10 \mathrm{~m}$ de profundidade, compostos por solo argiloso. Em todos os modelos foram usados os mesmos materiais para representear as tubulações e fluidos que os preenchiam, sendo os tubos constituídos de: PVC (policloreto de vinila), aço, concreto e cerâmica. $E$ os fluidos que os preenchiam eram: água, gasolina e ar. Para a simulação foram usados os seguintes parâmetros físicos: permissividade dielétrica, condutividade e permeabilidade magnética (Tabela 1). As tubulações tinham $0,2 \mathrm{~m}$ de espessura e $0,4 \mathrm{~m}$ de raio. O software GPRSim.net também foi utilizado para o estudo do comportamento do sinal, esse é uma ferramenta básica de simulação do método GPR no domínio de tempo, para freqüências variando de 200 a $2000 \mathrm{MHz}$. Ele pode ser usado para experimentar diferentes cenários de pesquisa do mundo real e entender como diferentes antenas de freqüência central, os mesmos parâmetro físicos foram utilizados na simulação.

Tabela 1- Parâmetros Físicos.

\begin{tabular}{|l|c|c|c|}
\hline Material & $\begin{array}{c}\text { Permissivida } \\
\text { de } \\
\text { Dielétrica }\end{array}$ & $\begin{array}{c}\text { Conduti } \\
\text { vidade }\end{array}$ & $\begin{array}{c}\text { Permeabilid } \\
\text { ade } \\
\text { magnética }\end{array}$ \\
\hline $\begin{array}{l}\text { Solo } \\
\text { Argiloso }\end{array}$ & 18 & 0 & 1 \\
\hline PVC & 8 & 0 & 1 \\
\hline Aço & 1 & 0 & 1 \\
\hline Concreto & 7 & 0 & 1 \\
\hline Cerâmica & 6 & 0 & 1 \\
\hline Água & 80 & 0 & 1 \\
\hline Gasolina & 2 & 0 & 1 \\
\hline Ar & 1 & 0 & 1 \\
\hline
\end{tabular}

Para simular as reflexões da onda eletromagnética (EM) na superfície do meio foi utilizado como fonte eletromagnética o modo, exploding reflector, campo de ondas, ou seja, as ondas são geradas simultaneamente a partir do alvo refletor e enviadas para a superfície, simulando uma seção de GPR zero-offset (Yilmaz, 1987). Usou-se para condições de contorno o modo, linear absorbing-range que limita no espaço a região infinita, proporcionando uma diminuição de reflexões espúrias dos contornos do modelo, através do aumento gradativo da condutividade, alcançando um valor máximo nas extremidades. O modelo é discretizado em um grid composto por um conjunto finito de pontos $\Delta x=0,025$ e $\Delta t=0.04$.

Geralmente, para identificar uma tubulação é verificada a forma de hipérbole quando o perfil de aquisição do GPR 
cruza ortogonalmente acima do eixo da tubulação. A amplitude de onda do sinal de radar é máxima sempre que a antena atravessa ortogonalmente 0 eixo da tubulação. No entanto, quando a antena passa paralelamente acima do eixo da tubulação, a hiperbola (assinatura de reflexão) tem uma forma totalmente diferente, que não é mais hiperbólica. Em um caso extremo, quando a trajetória da antena está ao longo do eixo da tubulação, a hipérbole é distorcida em linha reta. A forma da hipérbole e o tipo de picos (máximo ou mínimo) depende do material utilizado. Ao analisar os dados acima, é possível definir o tipo e o material do utilitário. Nesse trabalho a polaridade da reflexão é positiva (normal) para a reflexão em uma interface com contraste de velocidade baixa a alta e a polaridade da reflexão é negativa (reversa) para a reflexão em uma interface com contraste de velocidade alta a baixa.

\section{Modelagem e Resultados}

Os modelos e seus resultados são apresentados de acordo com a disposição das tubulações. As tubulações estão em (I) mesma profundidade $(2.5 \mathrm{~m})$ e (II) profundidades diferentes $(2.5 \mathrm{~m}, 3.5 \mathrm{~m}, 4.5 \mathrm{~m}$ e $5.5 \mathrm{~m})$..

A migração utilizada nos dados simulados foi a Kirchhoff com valor de velocidade obtido pela análise da curva de difração (hipérbole), com posicionamento do verdadeiro ponto refletor. O posicionamento dos tubos do modelo sintético foram com o valor de velocidade da onda em $0,073 \mathrm{~m} / \mathrm{ns}$.

(I) Mesma profundidade

$\mathrm{Na}$ Figura 2 as tubulações estão em mesma profundidade com as tubulações na seguinte ordem: PVC, aço, concreto e cerâmica.

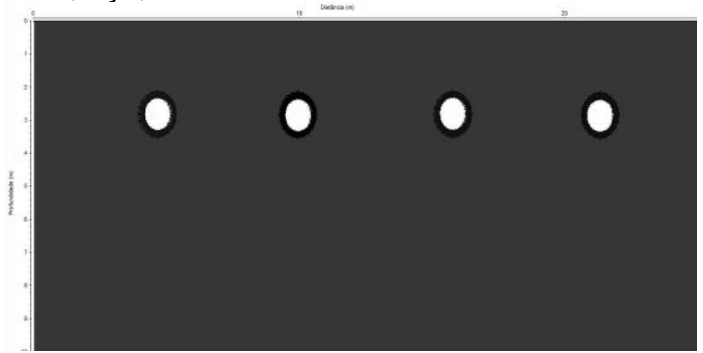

Figura 2 - Modelo físico com as tubulações em mesma profundidade. PVC, aço, concreto e cerâmica (em ordem da esquerda para a direita).

Os resultados obtidos serão apresentados diferenciando o tipo de fluido. Os vértices dos refletores hiperbólicos são interpretados como o topo das tubulações, marcando a diferenciação do material do tubo com o solo argiloso e o fluido.

(a) Água

Na Figura 3 são destacadas 4 primeiras hipérboles em 60 ns e suas múltiplas logo abaixo da primeira hipérbole. Para as diferentes tubulações é possível verificar que a tubulação de aço preenchida com água (seta em vermelho), as múltiplas não possuem alta amplitude devido a atenuação da onda no meio (água). Na Figura 4 são analisados os traços sobre as tubulações sendo verificado que a tubulação de aço com água em seu topo apresenta polaridade normal (seta em vermelho), devido a alta permissividade da água todas as tubulações também apresentam polaridade normal. O sinal aparece similar nas figuras (a), (c) e (d) o que indica que ao ser detectado as tubulações de PVC, concreto e cerâmica com água será difícil de discerni-lás. Também é verificado na figura 4 (a) que o sinal para o fluido (água) tem pequeno comprimento de onda. Observa-se o eixo do tempo de reflexão a 409,37 s, devido a velocidade relativamente baixa das ondas EM na água.

A Figura 5 mostra o resultado do uso da migração, como os valores de velocidade para as múltiplas ficaram abaixo do valor obtido das primeiras hipérboles, não houve um ajuste dessas com suas concavidades sendo voltadas para cima. Também é verificado que para própria tubulação a velocidade precisaria ser ajustada a um valor pouco acima do utilizado.

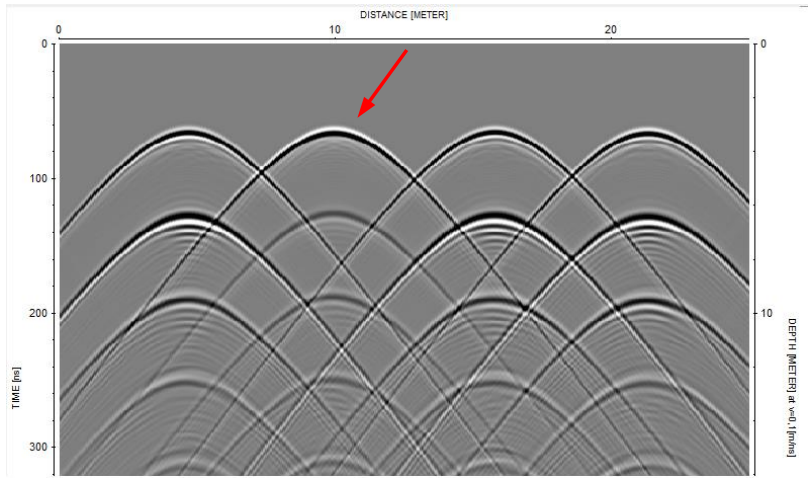

Figura 3 - Seção radargrama. Na figura as hipérboles representam as difrações nas tubulações de PVC, aço, concreto e cerâmico (respectivamente).

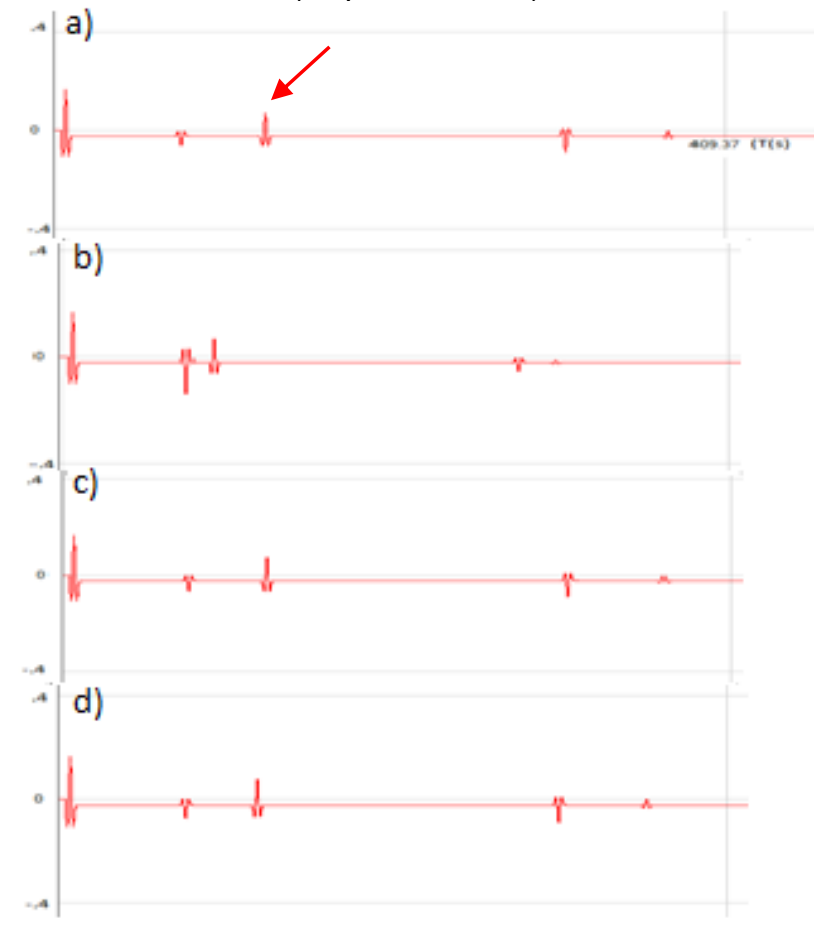

Figura 4 - Sinal da onda EM para as tubulações de PVC, Aço, Concreto e Cerâmica em antena de $200 \mathrm{MHz}$ com água. 


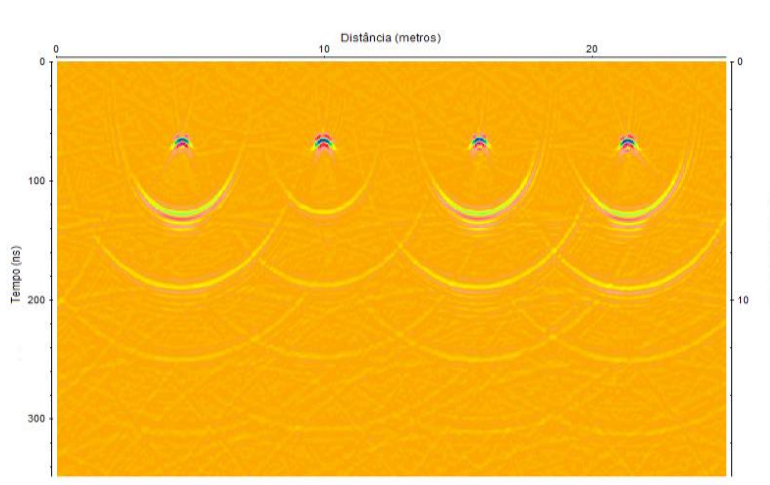

Figura 5 - Seção radargrama com migração Kircchoff. PVC, aço, concreto e cerâmica (em ordem da esquerda para a direita).

(b) Gasolina

Na Figura 6 são destacadas hipérboles em 60 ns e suas múltiplas. Para as diferentes tubulações é possível verificar que para a tubulação de aço, as múltiplas possuem forte amplitude (seta em vermelho). É verificado também que a primeira tubulação de PVC com gasolina (seta laranja) como as tubulações de concreto e cerâmica apresentam maior comprimento de onda. Na figura 7 no vértice da hipérbole (no topo da tubulação) o sinal apresenta polaridade reversa como as demais tubulações (seta verde), a onda ao passar da espessura da tubulação para a gasolina apresenta polaridade normal (seta em azul), as outras hipérboles representando as outras tubulações geram refletores de polaridade reversa. $\mathrm{Na}$ Figura 8 são analisados os traços sobre as tubulações sendo verificado que a tubulação de aço com gasolina em seu topo não apresenta polaridade reversa, o sinal aparece similar nas figuras (a), (c) e (d) o que indica que ao ser detectado as tubulações de PVC, concreto e cerâmica com gasolina será difícil de discernilás. Observa-se o eixo do tempo de reflexão a 204,68 s, devido a velocidade alta das ondas EM no meio. Na figura $7 \mathrm{~b}$ as reflexões da espessura da tubulação com o fluido e o meio são menos separadas no tempo. Na Figura 8 foi possível verificar que através da migração houve o posicionamento do verdadeiro ponto refletor.

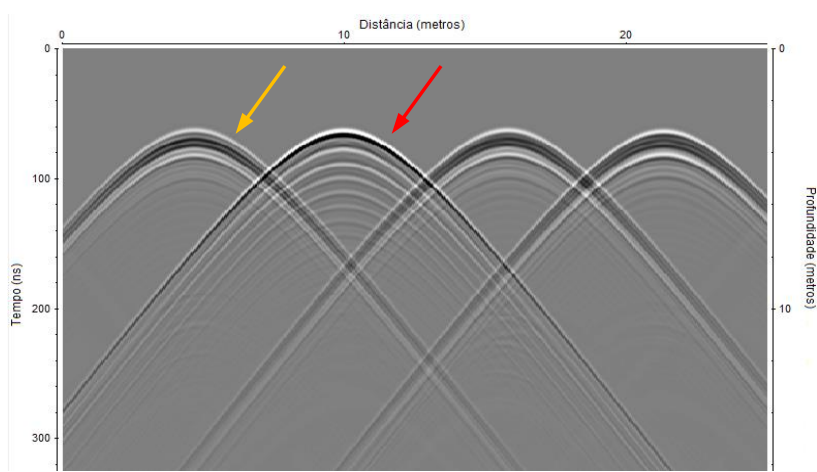

Figura 6 - Seção radargrama. Na figura as hipérboles representam as difrações nas tubulações de PVC, aço, concreto e cerâmico (respectivamente).
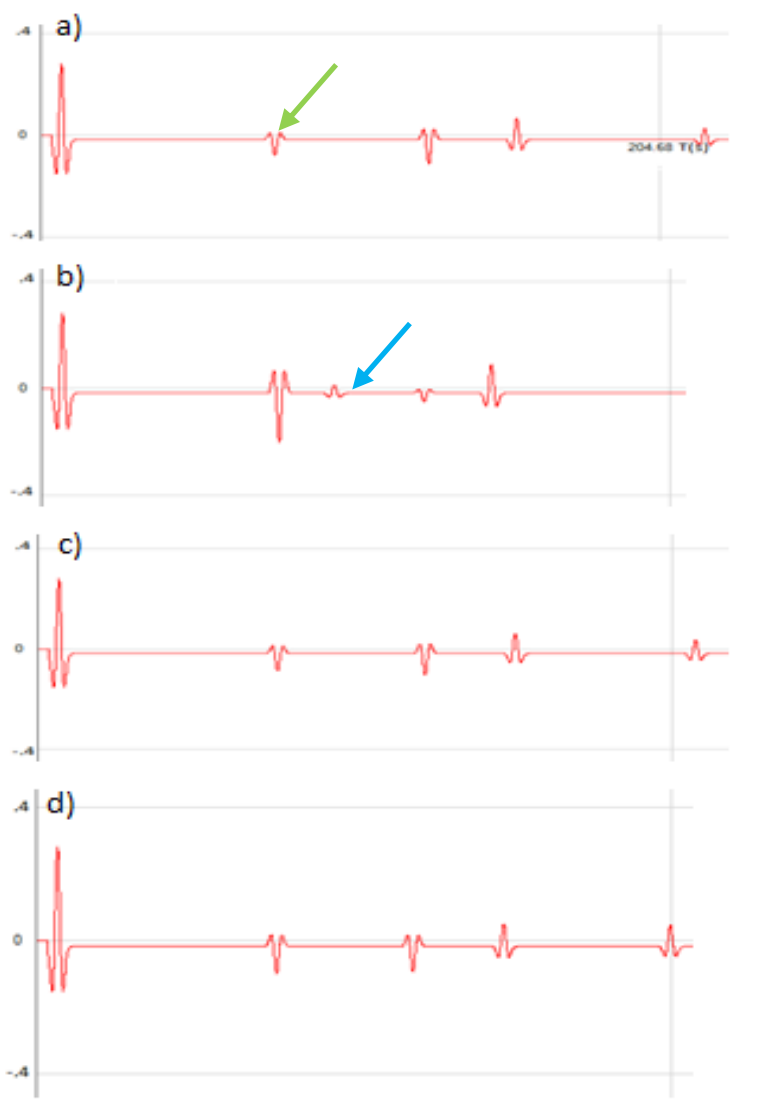

Figura 7 - Sinal da onda EM para as tubulações de PVC, Aço, Concreto e Cerâmica em antena de $200 \mathrm{MHz}$ com gasolina.

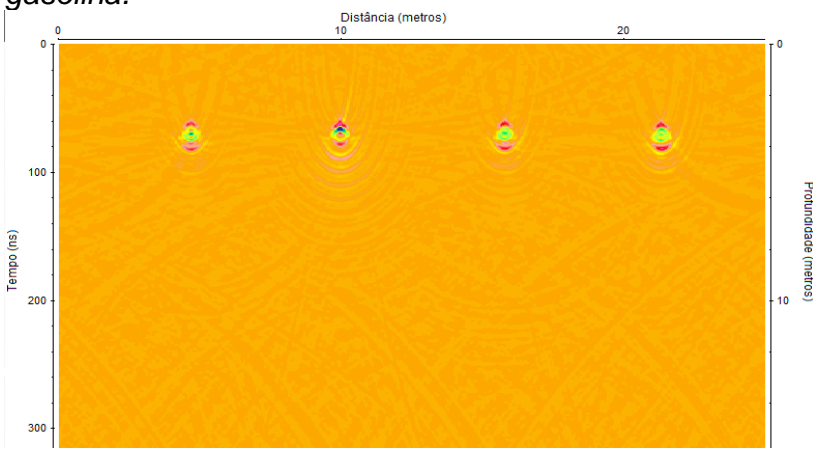

Figura 8 - Seção radargrama com migração Kircchoff. PVC, aço, concreto e cerâmica (em ordem da esquerda para a direita).

(c) $\mathrm{Ar}$

$\mathrm{Na}$ Figura 9 são destacadas as hipérboles em 60 ns e suas múltiplas. Como os demais resultados a tubulação de aço gerou um forte refletor (seta em vermelho). Para todas as reflexões foram gerados refletores com polaridade reversa, sendo que a do aço apresenta menor comprimento de onda que os demais tipos de tubulação (seta em verde). Na Figura 10 são analisado os traços sobre as tubulações sendo verificado que a tubulação de aço com ar em seu topo não apresenta polaridade reversa, o sinal aparece similar nas figuras (a), (c) e (d) o que indica que ao ser detectado as tubulações de PVC, concreto e cerâmica com ar será difícil de discerni-lás. Observa-se o eixo do tempo de reflexão a 204,68 s, 
devido a velocidade alta das ondas EM no meio. Na figura 10 (a) os reflexos da espessura da tubulação não são verificados, somente da parte de topo e fundo da tubulação com o meio. Na Figura 11 foi possível verificar que através da migração houve o posicionamento do verdadeiro ponto refletor.

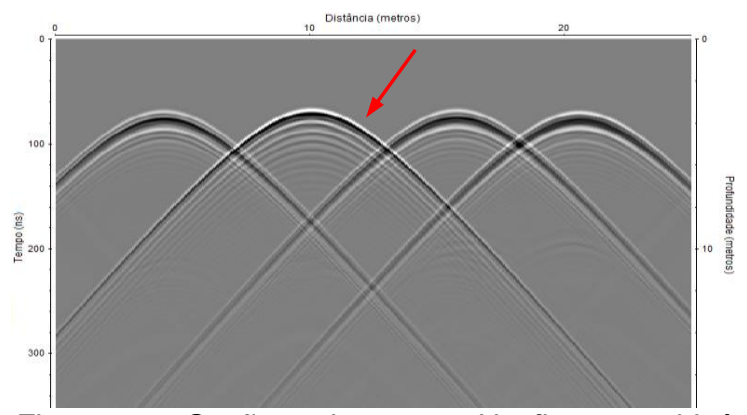

Figura 9 - Seção radargrama. Na figura as hipérboles representam as difrações nas tubulações de PVC, aço, concreto e cerâmico (respectivamente).

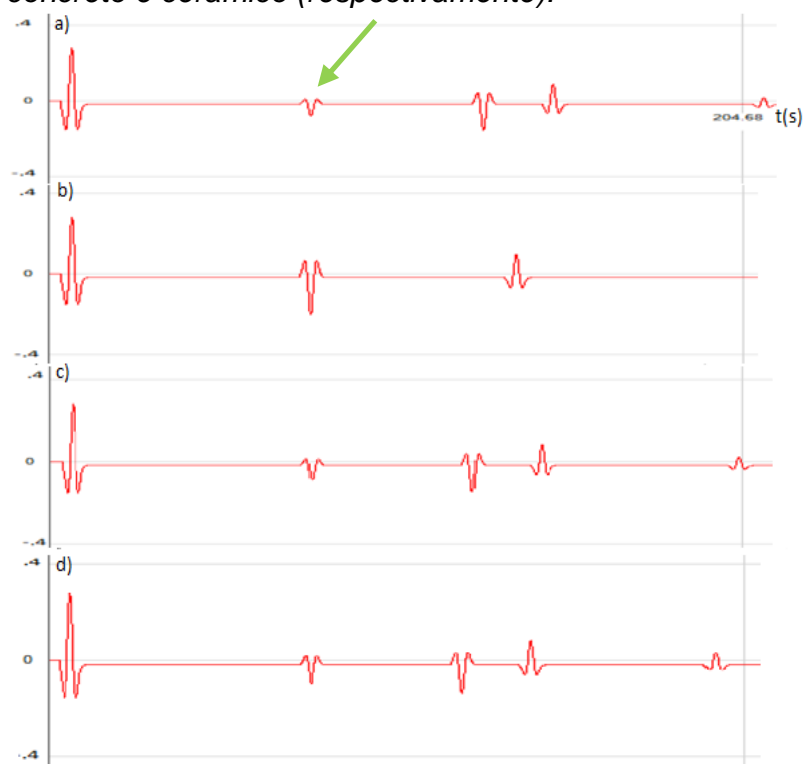

Figura 10 - Sinal da onda EM para as tubulações de PVC, Aço, Concreto e Cerâmica em antena de $200 \mathrm{MHz}$ com ar.

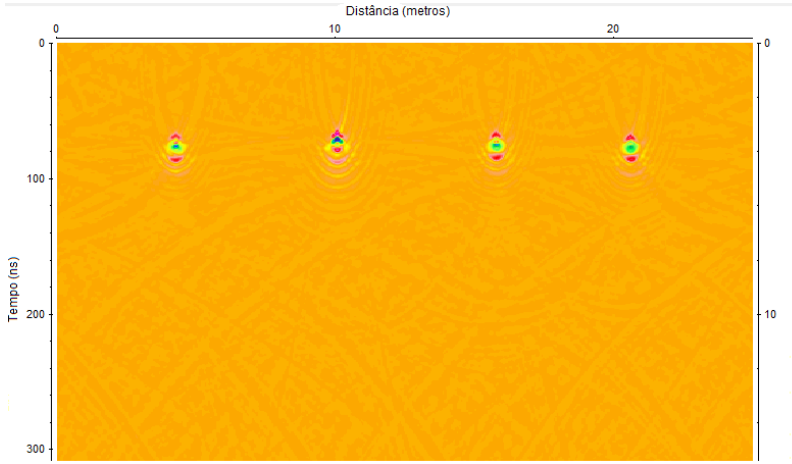

Figura 11 - Seção radargrama com migração Kircchoff. PVC, aço, concreto e cerâmica (em ordem da esquerda para a direita).

(II) Profundidades diferentes
O modelo na figura 12 representa as tubulações seguindo a seguinte ordem de materiais: PVC, aço, concreto e cerâmica.

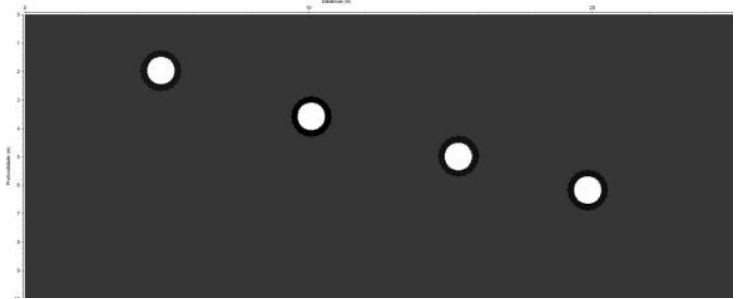

Figura 12 - Modelo geológico GPR com profundidades diferentes. PVC, aço, concreto e cerâmica (em ordem da esquerda para a direita).

(a) Agua

$\mathrm{Na}$ Figura 13 são destacadas quatro hipérboles em diferentes profundidades e suas múltiplas. Para as diferentes tubulações é possível verificar que a tubulação de aço preenchida com água, as múltiplas não possuem forte amplitude (seta em vermelho). Entre o meio e os dois materiais aço (tubo) e água (fluido) a hipérbole tem um refletor branco e preto (polaridade reversa), sendo que para as demais tubulações os fluidos geram um refletor branco, preto e branco. Apesar das tubulações estarem em profundidades diferentes foram possíveis verificar a presença das quatro tubulações. A Figura 14 no uso da migração é verificado que o valor de velocidade para as múltiplas ficaram abaixo do valor obtido. Para a primeira tubulação, não houve um ajuste da hipérbole ao ponto refletor, mas as demais tubulações apresentaram um melhor ajuste.

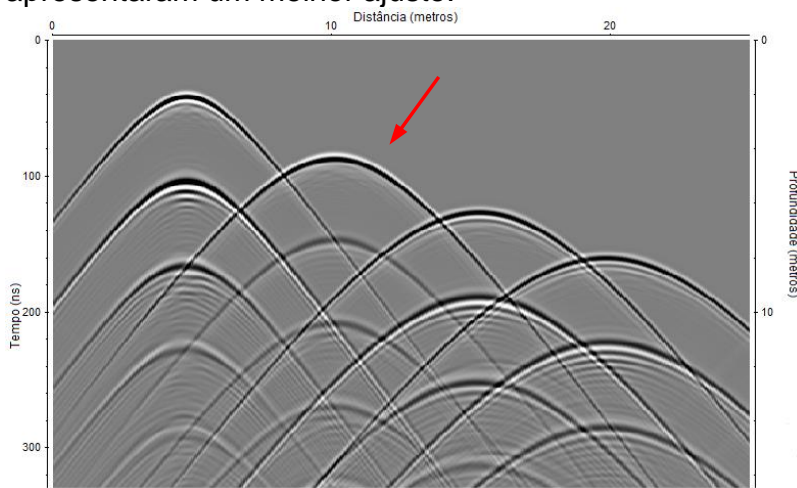

Figura 13 - Seção radargrama. Na figura as hipérboles representam as difrações nas tubulações de PVC, aço, concreto e cerâmico (respectivamente).

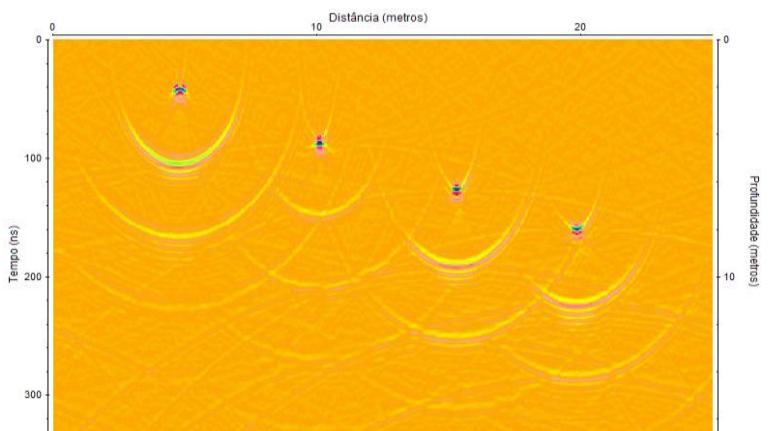

Figura 14 - Seção radargrama com migração Kirchhoff. PVC, aço, concreto e cerâmica (em ordem da esquerda para a direita). 


\section{(b) Gasolina}

$\mathrm{Na}$ Figura 15 são destacadas quatro hipérboles em diferentes profundidades. Para as diferentes tubulações preenchidas com gasolina é possível verificar a diminuição na amplitude dos refletores, devido ao baixo valor de permissividade dielétrica da gasolina. A tubulação de aço apresenta múltiplas de alta amplitude (seta em vermelho). A hipérbole correspondente ao aço produz polaridade reversa como para as demais tubulações, sendo que em menor comprimento de onda. $\mathrm{Na}$ figura 16 para a primeira e segunda tubulação, não houve um ajuste da hipérbole ao ponto refletor, mas as demais tubulações apresentaram ajuste.

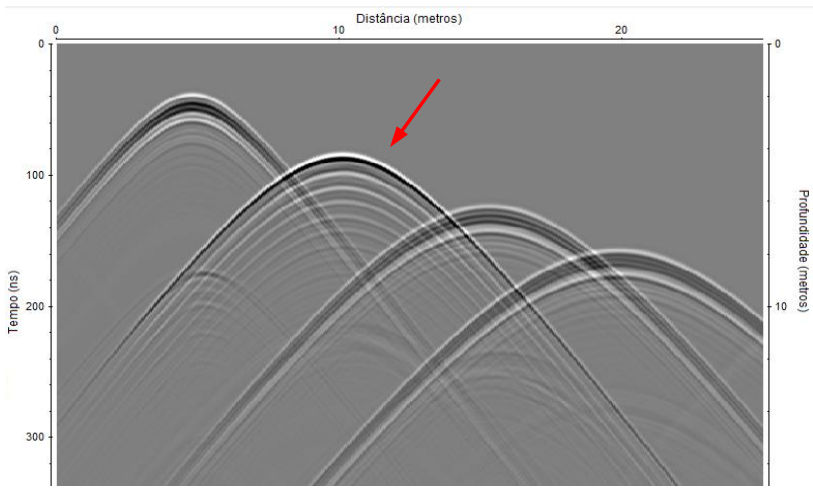

Figura 15 - Seção radargrama. Na figura as hipérboles representam as difrações nas tubulações de PVC, aço, concreto e cerâmico (respectivamente).

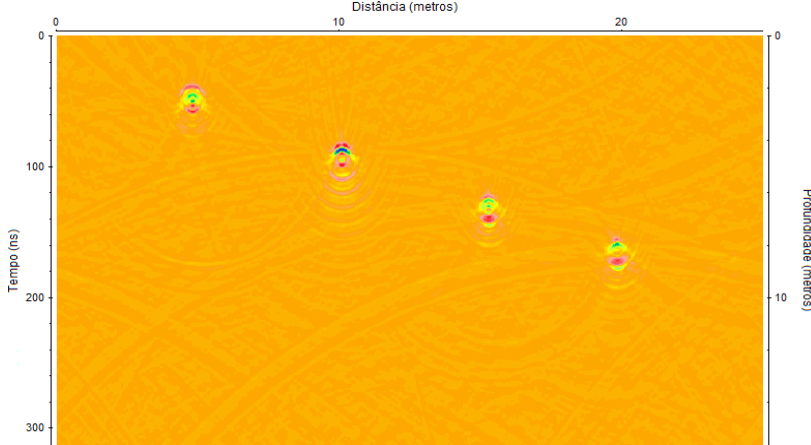

Figura 16 - Seção radargrama com migração Kircchoff. PVC, aço, concreto e cerâmica (em ordem da esquerda para a direita).

(c) $\mathrm{Ar}$

$\mathrm{Na}$ Figura 17 são destacadas hipérboles em diferentes profundidades. Para as diferentes tubulações é possível verificar que as tubulações de, concreto e cerâmica, se mostram com refletor mais fraco em comparação as hipérboles de aço e PVC. Da mesma forma que para a gasolina a tubulação de aço apresenta menor comprimento de onda.

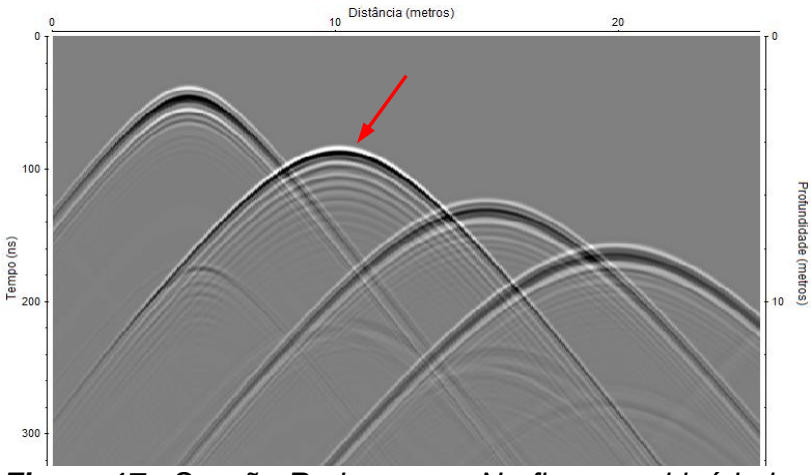

Figura 17- Secção Radargrama. Na figura as hipérboles representam as difrações nas tubulações de PVC, aço, concreto e cerâmico (respectivamente).

Na figura 18 apresenta o resultado da migração kircchoff com a velocidade da onda de 0,073 $\mathrm{m} / \mathrm{ns}$.

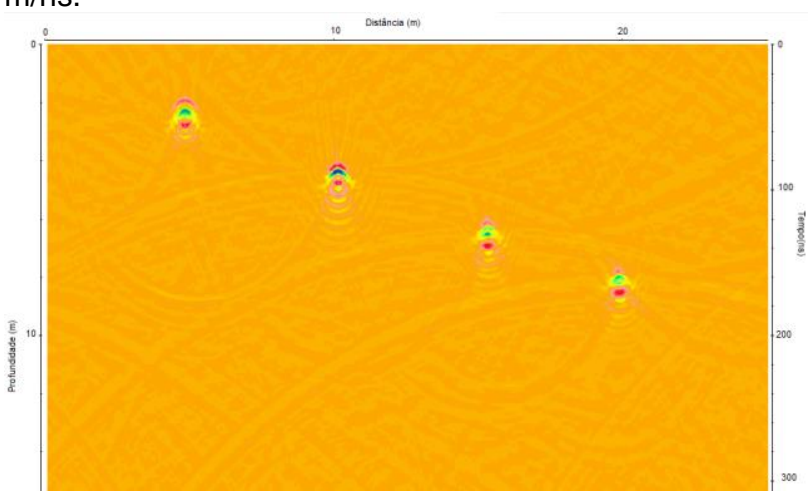

Figura 18 - Seção radargrama com migração Kircchoff. PVC, aço, concreto e cerâmica (em ordem da esquerda para a direita).

\section{Conclusão}

Pelo estudo foi possível observar que a antena com frequência de $100 \mathrm{MHz}$ consegue um bom imageamento das tubulações em mesma e diferentes profundidade. Foi verificado que para os diferentes tipos de tubulações preenchidas com água essas fornecem uma alta resposta em amplitude e menor comprimento de onda. Sendo que para o tubo de aço preenchido com diferentes tipos de fluidos, essa também apresenta alta amplitude. Mas pode-se destacar que quando preenchido com água nas diferentes tubulações ocorre a presença de múltiplas (ringing) que o distingue dos demais. Para os tubos, PVC, concreto e de cerâmica, essas apresentam características semelhantes em resposta da onda eletromagnética refletida (amplitude), não importando a profundidade ou fluido. É visto na modelagem que a forma da hipérbole e a amplitude dependem da profundidade e do tipo material, da tubulação e fluido, que é usado para a simulação. Para a análise do sinal a $200 \mathrm{MHz}$, também conforme a antena de $100 \mathrm{MHz}$, as tubulações não metálicas são difíceis de serem discernidas, ressaltando-se a presença da tubulação metálica. Pode se ainda afirmar que não houve reflexões de borda, mostrando a eficácia do contorno, linear absorbing-range, utilizado. Os resultados também mostraram a efetividade do uso da modelagem FDTD nas simulações de dados sintéticos para testar 
parâmetros, modelos, localização de tubulações para aquisições com o GPR. A velocidade obtida para a migração Kircchoff utilizada nos dados recuperou efetivamente a amplitude de reflexão e a localização das tubulações, sendo que para as múltiplas não houve o ajuste da hipérbole devido a diminuição do valor da velocidade da hipérbole em profundidade $(2 t=x / v)$.

\section{Agradecimentos}

Ao laboratório de Geofísica da UFRJ.

\section{Referências}

DIAS, G. A. N. Modelagem e Imageamento dos Dados de GPR Adquiridos em Afloramentos Visando o Estudo de Reservatório Petrolífero. Rio de Janeiro, 2007. Tese (Doutorado em Geociências) - Instituto de Geociências, Universidade Federal do Rio de Janeiro, 2007.

Lima, R. S.. 2006. Otimização de Perfis de Reflexão GPR sobre manilhas de concreto e tubulações de PVC instalados no Sítio Controlado de Geofísica Rasa do IAG-USP. Dissertação de Mestrado, IAG-USP, São Paulo. 130p.

Smitha, N.; Ullas B. J D.R.; Abilash, S; Sridhara S. N. ; Singh V. 2016. Kirchhoff and F-K migration to focus ground penetrating radar image. Geo-Engineering 7: 4. doi:10.1186/s40703-016-0019-6.

Taflove A. 1980. Application of the Finite-Difference Time-Domain Method to Sinusoidal Steady-State Electromagnetic-Penetration Problems. IEEE Transactions on Electromagnetic Compatibility ( Volume: EMC-22, Issue: 3, Aug.)

Zeng X. and McMechan G. A.. GPR characterization of buried tanks and pipes. GEOPHYSICS, VOL. 62, NO. 3 (MAY-JUNE 1997); P. 797-806, 10 FIGS., 2 TABLES.

Wexler A, 1969. Computation of electromagnetic fields, IEEE Trans. on MTT, 17-8, 416-439.

YILMAZ, O., Seismic Data Processing. Tulsa: Society of Exploration Geophysicists, 1987 